\title{
Blood pressure and metabolic control as risk factors for nephropathy in Type 1 (insulin-dependent) diabetes
}

\author{
Ch. Hasslacher, W. Stech, P. Wahl and E. Ritz \\ Department of Internal Medicine, University of Heidelberg, Heidelberg, FRG
}

Summary. The respective rôles of arterial blood pressure and metabolic control in different stages of diabetic nephropathy were analyzed retrospectively in 52 sequentially-followed Type 1 (insulin-dependent) diabetic patients. A negative correlation was found between median post-prandial blood glucose and median duration of diabetes until onset of persistent proteinuria $(p<0.01)$. Systolic blood pressure was higher in patients who subsequently developed persistent proteinuria than those who did not (140 versus $121 \mathrm{mmHg} ; p<0.05)$, but duration of the interval until onset of persistent proteinuria was not related to blood pressure. After onset of persistent proteinuria, hypertensive diabetic patients developed elevated serum creatinine concentrations more frequently than normo- tensive diabetic patients ( $67 \%$ versus $14 \%, p<0.05$ ). In these patients, the delay until elevation of serum creatinine concentration was negatively correlated with blood glucose $(p<0.01)$. Once serum creatinine was raised, decay of renal function occurred faster in patients with persistent than intermittent hypertension $(p<0.05)$. No effect of metabolic control was demonstrable at this stage of nephropathy. It is concluded that metabolic control determines the early course of diabetic nephropathy, whereas blood pressure is more important in advanced stages of nephropathy.

Key words: Type 1 diabetes, diabetic nephropathy, blood pressure, metabolic control.
Recent concepts on the pathogenesis of diabetic nephropathy have emphasized the importance of metabolic control and glomerular haemodynamics [1-8]. Although there is general consensus with respect to the rôle of blood pressure on the course of overt clinical nephropathy, there is little and conflicting information on the rôles of blood pressure in the pre-proteinuric stage $[8,9]$ and of metabolic control in the proteinuric stage [10-12], respectively.

The present retrospective study was designed to examine these points. Therefore, a group of systematically-controlled sequentially followed Type 1 diabetic patients were examined to elucidate the respective rôles of metabolic control and blood pressure. Post-prandial blood glucose and blood pressure at entry were compared for patients who did and for patients who did not develop clinical nephropathy. The predictive value of these factors on the clinical course of this complication was assessed.

\section{Subjects and methods}

\section{Subjects}

Three hundred and twenty-four Type 1 diabetic patients (153 men, 171 women) attended the diabetic outpatient clinic of the Department of Internal Medicine, Heidelberg, for at least 1 year between 1966 and 1983. Patients were referred either at the time of diagnosis for advice on treatment, or when referring physicians had problems with metabolic control. Eighty patients developed persistent proteinuria (at least four Combur-positive urines [Boehringer Mannheim, Mannheim FRG] during a 6-month period, protein excretion $>0.5 \mathrm{~g} / 24 \mathrm{~h}$ ) with or without elevated serum creatinine levels. The diabetic patients with persistent proteinuria were classified as having clinical nephropathy and were entered into the study if they fulfilled the following criteria: (1) onset of persistent proteinuria after a total duration of diabetes of at least 7 years and after exclusion of other renal disease by clinical studies (bacteriological and microscopic investigation of urine; if indicated, further examination with X-ray or ultrasound); (2) no proteinuria at time of first visit to the outpatient clinic; (3) at least five blood glucose and blood pressure measurements per year; (4) no severe systemic disease, i. e. carcinoma, cardiac insufficiency, active chronic aggressive hepatitis.

Fifty-two diabetic patients fulfilled these criteria. The median duration of observation before the onset of persistent proteinuria was 6 years (range 2.5-11 years). Twenty-five of these patients had intermittent proteinuria, i. e. occasional Combur-positive urines at the time of referral. All patients had developed retinopathy (background $n=44$, proliferative $n=8$ ) at time of onset of persistent proteinuria.

All patients with long-standing diabetes ( $>20$ years), who had never had intermittent or persistent proteinuria and fulfilled criteria 3 and 4 above, were studied as a control group $(n=30)$. The frequency of background retinopathy was $40 \%$ at time of entry and $65 \%$ by the end of the study. Nine percent of the patients developed proliferative retinopathy during the follow-up period.

\section{Methods}

All patients attended the clinic at 4-8 weeks intervals. The following measurements from the patients records were analyzed:

Blood glucose was analyzed enzymatically in capillary blood 60-90 min after breakfast. 
Table 1. Characteristics of the patients studied

\begin{tabular}{|c|c|c|c|c|c|c|c|}
\hline & $\begin{array}{l}\text { Sex } \\
M: F\end{array}$ & $\begin{array}{l}\text { Age at onset } \\
\text { of diabetes } \\
\text { (years) }\end{array}$ & $\begin{array}{l}\text { Age at entry } \\
\text { to study } \\
\text { (years) }\end{array}$ & $\begin{array}{l}\text { Duration of } \\
\text { diabetes at } \\
\text { entry to study } \\
\text { (years) }\end{array}$ & $\begin{array}{l}\text { Body mass index } \\
\text { at entry to study } \\
\left(\mathrm{kg} / \mathrm{m}^{2}\right)\end{array}$ & $\begin{array}{l}\text { Outpatient } \\
\text { attendances } \\
\text { (per year) }\end{array}$ & $\begin{array}{l}\text { Duration of } \\
\text { follow-up } \\
\text { (years) }\end{array}$ \\
\hline $\begin{array}{l}\text { Diabetic patients with } \\
\text { nephropathy }(n=52)\end{array}$ & $22: 30$ & $\begin{array}{l}26 \\
(1-40)\end{array}$ & $\begin{array}{l}40 \\
(16-60)\end{array}$ & $\begin{array}{l}13 \\
(1-24)\end{array}$ & $\begin{array}{l}23 \\
(18-29)\end{array}$ & $\begin{array}{l}9 \\
(5-19)\end{array}$ & $\begin{array}{l}11 \\
(6-16)\end{array}$ \\
\hline $\begin{array}{c}\text { Diabetic patients withou } \\
\text { nephropathy }(n=30)\end{array}$ & $13: 17$ & $\begin{array}{l}23 \\
(4-39)\end{array}$ & $\begin{array}{l}32 \\
(17-52)\end{array}$ & $\begin{array}{l}11 \\
(1-20)\end{array}$ & $\begin{array}{l}22 \\
(19-30)\end{array}$ & $\begin{array}{l}11 \\
(5-16)\end{array}$ & $\begin{array}{l}13 \\
(7-16)\end{array}$ \\
\hline
\end{tabular}

Results are given as median with range in parentheses

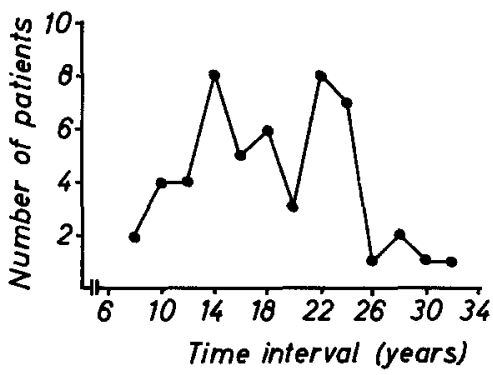

Fig. 1 Time interval between diagnosis of diabetes and onset of persistent proteinuria in 52 Type 1 diabetic patients

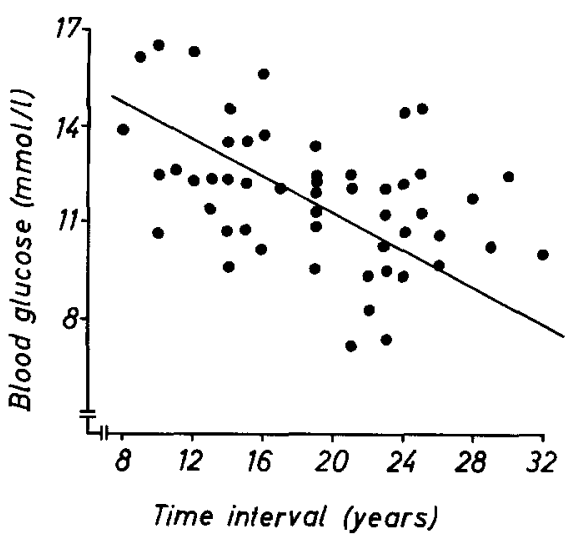

Fig. 2 Correlation between metabolic control and onset of persistent proteinuria in 52 Type 1 diabetic patients. Median post-prandial blood glucose during the pre-proteinuric stage and time interval between diagnosis of diabetes and onset of persistent proteinuria are shown $(r=0.40 ; p<0.01)$

Proteinuria was measured in 24-h urinary collection (plastic bottles, no preservative) with Combur test strip. Protein concentrations, particularly albumin [13], can be semi-quantitatively determined in the range between $0.3-5.0 \mathrm{~g} / 1$ using this test strip. Incorrect results due to interaction with drugs, such as quinine, quinidine, penicillin etc., could be excluded.

Serum creatinine was measured at 12 -month intervals in patients with normal serum creatinine levels $(55-133 \mu \mathrm{mol} / 1)$. When serum creatinine was $>133 \mu \mathrm{mol} / 1$, patients were examined more frequently (maximum of 6 months). Until 1972, a manual Jaffe method utilizing unprocessed serum was used [14]; after 1972, the Technicon SMA II C Autoanalyzer (Technicon Corporation, Tarrytown, New York, USA) was used; here pseudocreatinine levels were eliminated by a dialysis step. None of the patients had acidosis at the time of serum creatinine measurement. No elevation of serum creatinine $>133 \mu \mathrm{mol} / 1 \mathrm{oc}-$ curred in any of the patients before 1972 .
Blood pressure, systolic (phase I) and diastolic (phase V), was measured at each visit after $5-10$ min rest in the sitting position in a separate room by one of three nurses who were working in the outpatient clinic from 1966 to 1983 . Measurements were made with a calibrated standard mercury manometer, the accuracy of which was controlled at 12-month intervals. The bladder width was $12 \mathrm{~cm}$.

Body weight was recorded as body mass index $\left(\mathrm{kg} / \mathrm{m}^{2}\right)$ using a standard balance with light indoor clothing, but no shoes.

\section{Metabolic control and anti-hypertensive therapy}

Advice as to diet and insulin was given by one of the two physicians who were involved in patient care throughout the study period. Eighty percent of patients were given two injections of insulin per day. The remainder injected insulin either once (14\%) or several times per day $(6 \%)$. For treatment surfen (Hoechst) or protamine-containing insulins were normally used. During the last $6-8$ years of the observation period, home monitoring of glucose was carried out by most patients [56\% blood glucose with Haemo-Glukotest 20-800 (Boehringer Mannheim, Mannheim, FRG) or Dextrostix (Ames, Frankfurt, FRG) $; 25 \%$ urine glucose control using Glukotest (Boehringer Mannheim, Mannheim, FRG) and 19\% no self-control].

For treatment of blood pressure in the early 1970 s diuretics, reserpine and $\alpha$-methyldopa were normally used; thereafter, diuretics were usually combined with $\alpha$ - and $\beta$-receptor blocking agents. None of the treated hypertensive patients was normotensive throughout the observation period. Only $18 \%$ of these were taught to measure their own blood pressure. Five patients had taken oral contraceptives, but none was hypertensive.

\section{Classification of blood pressure}

Established hypertension was defined according to modified World Health Organisation criteria, when at least two measurements per year were $>160 \mathrm{mmHg}$ systolic and/or $>95 \mathrm{mmHg}$ diastolic and/or when the patient required anti-hypertensive medication. The hypertensive status of patients was classified as: no hypertension: blood pressure always $\leqslant 160 / \leqslant 95 \mathrm{mmHg}$, intermittent hypertension: blood pressure repeatedly, but not constantly $>160 />95 \mathrm{mmHg}$; persistent hypertension: blood pressure continuously $>160 />95 \mathrm{mmHg}$. Correlations were calculated using the overall medians of systolic and diastolic pressures, respectively.

\section{Termination of observation period}

Patient follow-up ended because of death, initiation of dialysis or loss to follow-up when patients moved away. For those patients continuing in the outpatient clinic, observation ended on 31 December 1983. At that time, 20 with clinical nephropathy and 16 without were still being followed in the outpatient clinic. Fourteen of the 52 diabetic patients developed persistent proteinuria, but none of those without died during the observation period. Causes of death according to clinical diagnosis were: renal failure (4), coronary heart disease (3), cere- 
Table 2. Presence of hypertension and time to onset of persistent proteinuria in 52 Type 1 diabetic patients

\begin{tabular}{lcccc}
\hline & Sex & Blood pressure (mmHg) & Blood glucose (mmol/1) & $\begin{array}{c}\text { Onset of persistent } \\
\text { proteinuria (years) }\end{array}$ \\
\hline No hypertension $(n=27)$ & $13: 14$ & $137 / 80(118-156 / 75-86)$ & $11.7(8.3-15.7)$ & $19(12-32)$ \\
Intermittent hypertension $(n=16)$ & $5: 11$ & $150 / 89(139-160 / 80-100)$ & $12.8(9.9-13.9)$ & $19(8-29)$ \\
Persistent hypertension $(n=9)$ & $4: 5$ & $175 / 95(157-207 / 90-115)$ & $11.4(7.9-12.9)$ & $19(9-30)$ \\
\hline
\end{tabular}

Results are given as median with range in parentheses

Table 3. Prevalence of hypertension, blood pressure, and blood glucose at the time of persistent proteinuria in diabetic patients with and without subsequent increase in serum creatinine concentration

\begin{tabular}{|c|c|c|c|c|c|c|c|c|}
\hline \multirow[t]{2}{*}{ Group } & \multirow[t]{2}{*}{$\begin{array}{l}\text { Sex } \\
M: F\end{array}$} & \multirow[t]{2}{*}{$\begin{array}{l}\text { Age } \\
\text { (years) }\end{array}$} & \multirow{2}{*}{$\begin{array}{l}\text { Duration of diabetes } \\
\text { at onset of persistent } \\
\text { proteinuria } \\
\text { (years) }\end{array}$} & \multicolumn{3}{|c|}{$\begin{array}{l}\text { Number of patients with } \\
\text { (prevalence of hypertension) }\end{array}$} & \multirow{2}{*}{$\begin{array}{l}\text { Blood } \\
\text { pressure } \\
(\mathrm{mmHg})\end{array}$} & \multirow[t]{2}{*}{$\begin{array}{l}\text { Blood glucose } \\
(\mathrm{mmol} / \mathrm{l})\end{array}$} \\
\hline & & & & No hypertension & $\begin{array}{l}\text { Intermittent } \\
\text { hypertension }\end{array}$ & $\begin{array}{l}\text { Persistent } \\
\text { hypertension }\end{array}$ & & \\
\hline \multirow{2}{*}{$\begin{array}{l}\text { Diabetic patients } \\
\text { with increase of } \\
\text { serum creatinine } \\
(n=25)\end{array}$} & \multirow[t]{2}{*}{$9: 16$} & \multirow{2}{*}{$\begin{array}{l}43 \\
(20-65)\end{array}$} & \multirow{2}{*}{$\begin{array}{l}16 \\
(8-32)\end{array}$} & \multirow[t]{2}{*}{$2(8 \%)^{\mathrm{a}}$} & \multirow[t]{2}{*}{$13(52 \%)$} & \multirow[t]{2}{*}{$10(40 \%)^{b}$} & $160(120-202)^{\mathrm{c}}$ & \multirow{2}{*}{$\begin{array}{l}12.5 \\
(8.5-16.4)\end{array}$} \\
\hline & & & & & & & $90(80-122)$ & \\
\hline \multirow{3}{*}{$\begin{array}{l}\text { Diabetic patients } \\
\text { without increase of } \\
\text { serum creatinine } \\
(n=23)\end{array}$} & \multirow{3}{*}{$10: 13$} & \multirow{3}{*}{$\begin{array}{l}42 \\
(17-63)\end{array}$} & \multirow{3}{*}{$\begin{array}{l}20 \\
(10-29)\end{array}$} & \multirow{3}{*}{$12(52 \%)^{\mathrm{a}}$} & \multirow{3}{*}{$9(39 \%)$} & \multirow{3}{*}{$2(9 \%)^{b}$} & & \multirow{3}{*}{$\begin{array}{l}10.3 \\
(5.4-16.9)\end{array}$} \\
\hline & & & & & & & $142(118-178)^{\mathrm{c}}$ & \\
\hline & & & & & & & $84(76-110)$ & \\
\hline
\end{tabular}

Results given as mean with range in parentheses. ${ }^{\mathrm{a}} p<0.05 ;{ }^{\mathrm{b}} p<0.05 ;{ }^{\mathrm{c}} p<0.01$ between the two groups

brovascular accident (3), sepsis (1), unknown (3). Three are currently on maintenance haemodialysis. Twelve with clinical nephropathy and 10 without have moved away.

\section{Statistical analysis}

All values are given as median and range. Differences between groups were tested with Wilcoxon's test or $\chi^{2}$-test as indicated. Linear regression analysis was used to calculate correlations.

\section{Results}

The patient's characteristics at the time of entry into the study are described in Table 1. Diabetic patients who subsequently developed nephropathy did not differ significantly from those who did not with respect to sex, age, age at onset of diabetes, median duration of diabetes at entry into the study or duration of follow-up. Body weight did not change significantly during the observation period.

In patients with subsequent nephropathy, persistent proteinuria was present after a median duration of 19 years (range $10-30$ years) and serum creatinine increased in 25 of these after a median duration of diabetes of 22 years (range 11-42 years). The time of onset of persistent proteinuria seems to be bimodally distributed with one peak at $14 / 15$ years and a second peak at $22 / 23$ years after diagnosis of diabetes (Fig. 1 ). In men, 14 developed proteinuria before and eight after 20 years of diabetes. In women, however, 15 developed proteinuria before and 15 after 20 years of diabetes.
The median post-prandial glucose concentrations during the first 6 years of observation were significantly higher in patients who did subsequently develop persistent proteinuria than those who did not -11.5 $\mathrm{mmol} / \mathrm{l}$ (range $7.9-15.5 \mathrm{mmol} / \mathrm{l}$ ) versus $10.1 \mathrm{mmol} / \mathrm{l}$ (range $7.2-14.5 \mathrm{mmol} / \mathrm{l})$ respectively $(p<0.05)$. Again, in the patients who subsequently developed nephropathy, a higher median systolic blood pressure was detected during the pre-proteinuric stage than in the control subjects - $140 \mathrm{mmHg}$ (range $115-196 \mathrm{mmHg}$ ) versus $121 \mathrm{mmHg}$ (range $105-168 \mathrm{mmHg}$ ) respectively $(p<0.05)$. Diastolic blood pressure was not different. The prevalence of established hypertension was $44 \%$ in the patients with subsequent persistent proteinuria and $7 \%$ in those without $(p<0.05)$. The differences between the two groups in median blood glucose, median blood pressure and prevalence of established hypertension remained significant, even when 25 patients of the group with subsequent nephropathy, referred at the stage of intermittent proteinuria, were omitted.

There was a striking increase in the prevalence of hypertension and in median blood pressure as nephropathy progressed; at the time of persistent proteinuria the prevalence of hypertension was $67 \%$, median blood pressure $148 / 88 \mathrm{mmHg}$, median age 43 years (range $20-69$ years). Corresponding data at time of increase of serum creatinine $>133 \mu \mathrm{mol} / 1$ were $92 \%$, $158 / 92 \mathrm{mmHg}$ and 45 years (range $22-69$ years) respectively. In contrast, metabolic control did not change substantially throughout the observation period (data not shown). 


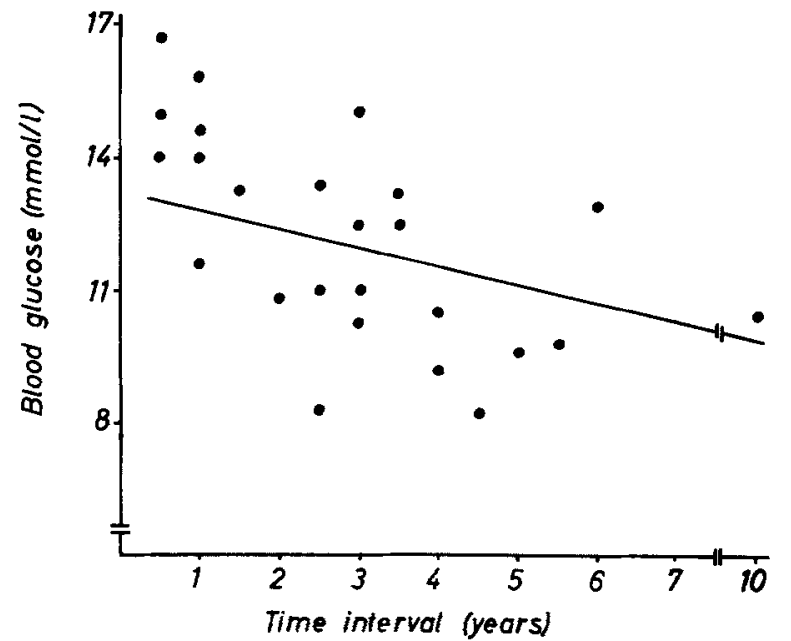

Fig.3 Correlation between metabolic control and onset of renal failure in 25 Type 1 diabetic patients. Median post-prandial blood glucose at time of persistent proteinuria and the time interval between onset of persistent proteinuria and elevation of serum creatinine are shown $(r=0.53 ; p<0.01)$

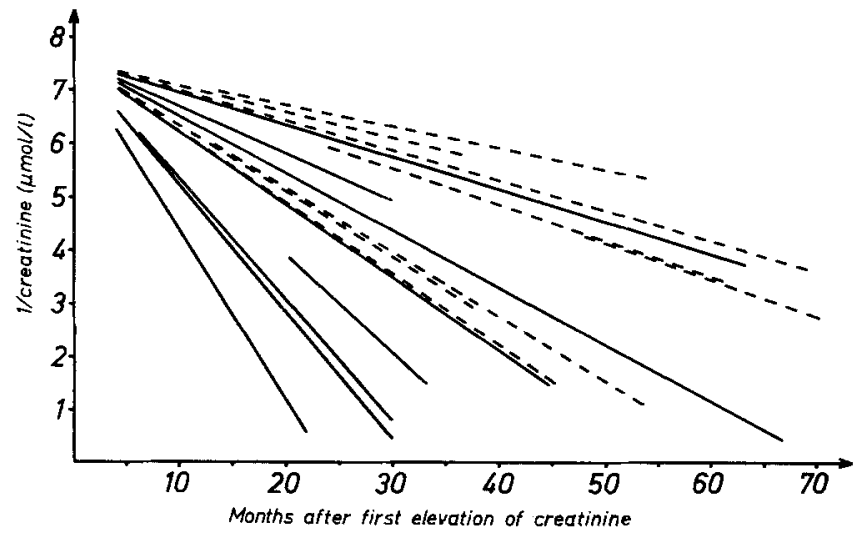

Fig. 4 Fall of glomerular filtration rate indicated by the reciprocal of serum creatinine ( $=1 /$ creatinine) versus time in eight diabetic patients with intermittent hypertension (---; median blood pressure $142 / 93 \mathrm{mmHg}$ ) and eight diabetic patients with persistent hypertension (- median blood pressure $182 / 94 \mathrm{mmHg}$ ). Patients were studied sequentially after serum creatinine had risen above $133 \mu \mathrm{mol} / \mathrm{l}$. Four determinations of serum creatinine per year were carried out in every patient. The mean slope of the reciprocal of serum creatinine versus time was 0.082 in diabetic patients with intermittent and 0.160 in those with persistent hypertension $(p<0.05)$

In patients who did not develop nephropathy, the prevalence of hypertension increased only to $17 \%$ and median blood pressure to $132 / 81 \mathrm{mmHg}$ by the end of the observation period. There was also no substantial change in metabolic control during follow-up. At the end of the observation time, these patients had a median age of 45 years (range $26-47$ years) and a median duration of diabetes of 24 years (range 20-31 years).

\section{Effect of metabolic control and blood pressure on onset of persistent proteinuria}

Among the diabetic patients who developed nephropathy, a negative correlation has been found between the median blood glucose levels and the time interval between diagnosis of diabetes and onset of persistent proteinuria (Fig. 2). This result cannot be explained by differences of blood pressure, since no correlation could be found between median blood glucose levels and median blood pressure. In contrast, blood pressure status had no predictive value with respect to the time interval between diagnosis and onset of persistent proteinuria (Table 2). Further sub-classification of normotensive patients, e.g. into median systolic blood pressure $<130 \mathrm{mmHg}(n=10)$ or $>130 \mathrm{mmHg}(n=12)$ similarly revealed no significant difference. There were no significant differences in post-prandial glucose levels between the three blood pressure groups.

\section{Effect of metabolic control and blood pressure on course of persistent proteinuria}

Four of the 52 patients who developed clinical nephropathy reached an endpoint of the study at the time of onset of persistent proteinuria (death 1 , moving away $3)$. The remainder $(n=48)$ were followed until elevation of serum creatinine, drop-out or the end of the study. In 25 serum creatinine rose above $133 \mu \mathrm{mol} / \mathrm{l}$ and in 23 no increase was observed during the follow-up period (median 3 years, range 1-13 years) in each group. The sex ratio, age and onset of nephropathy were similar in these two groups (Table 3 ). However, in patients who subsequently developed elevated serum creatinine, persistent hypertension was more prevalent ( $40 \%$ versus $8 \%$ ) and median systolic blood pressure was higher $(p<0.01)$. Diastolic blood pressure was not significantly different. No correlation was found between systolic blood pressure and the time interval between onset of persistent proteinuria and elevation of serum creatinine.

Blood glucose levels at the time of proteinuria were not significantly different in patients whose serum creatinine rose and those who did not $(0.05<p<0.1)$. However, in patients who developed renal failure, a correlation was found between the glucose levels at the time of proteinuria and the time interval between onset of persistent proteinuria and elevation of serum creatinine $(r=0.53, p<0.01 ;$ Fig. 3$)$. A similar correlation was found for the median of all post-prandial blood glucose values since entry into the study $(r=0.61, p<0.001)$.

\section{Effect of metabolic control and blood pressure on the course of renal failure}

Nine of the 25 patients who developed elevation of serum creatinine reached an endpoint of the study within a maximum of 4 months after the first increase of serum creatinine (death 2 , moving away 2 , end of observation 
$5)$. The remainder $(n=16)$ were followed for a median of 29 months (range 9-73 months) after serum creatinine had risen above $133 \mu \mathrm{mol} / 1$. Eight diabetic patients (3 men, 5 women; median age 47 years, range 25-69 years) had intermittent hypertension, eight (4 men, 4 women; median age 45 years, range 22-65 years) had persistent hypertension. Renal function, indicated by the reciprocal of serum creatinine versus time, decayed faster in patients with persistent compared with intermittent hypertension, but no correlation was found between the slope of the reciprocal of serum creatinine versus time and systolic or diastolic blood pressure, respectively (Fig.4). No correlation could be detected between concurrent blood glucose levels and decay of renal function.

\section{Discussion}

The main problems of retrospective studies are the possibilities of sampling error and of diagnostic criteria changing with time. In the present study all consecutive patients fulfilling the entry criteria were entered and the technique used for patient examination remained reasonably standardized throughout the observation period. Quantitative measurements of urinary protein excretion, and of $\mathrm{HbA}_{1}$, however, were not performed during the whole study period. One theoretical shortcoming of the study is the fact that anti-hypertensive therapy was introduced as a confounding variable. However, only a minority of patients had their blood pressure effectively controlled despite the prescription of such medication. The conclusions drawn from our observations concern actual blood pressure, irrespective of whether or not the patient was on medication. These blood pressure levels in treated patients represent the perfusion pressures to which the kidneys are exposed.

The present study shows that pre-proteinuric Type 1 diabetic patients who subsequently developed clinical nephropathy have a slight, but significant, elevation of systolic blood pressure and a higher prevalence of established hypertension compared with long-standing Type 1 diabetic patients without subsequent nephropathy. These results are in agreement with previously published studies $[9,15,16]$ which have found elevated blood pressure levels in diabetic patients with microalbuminuria. Although the difference of systolic blood pressure was not great in magnitude, this observation may be of interest with respect to the findings of Knowler et al. [15]. They noted that diabetic Pima Indians with low normal blood pressure developed less retinal damage than individuals with upper normal blood pressure $(<125$ versus $125-145 \mathrm{mmHg}$ systolic). However, in the present study, blood pressure did not influence the time interval between the onset of diabetes and the onset of proteinuria. Furthermore, an effect of blood pressure on even earlier stages of nephropathy (i. e. incipient nephropathy) could not be detected recently [16].
These findings suggest that a rise in blood pressure in pre-proteinuric diabetic patients is not of major pathogenic importance for the onset of clinical nephropathy.

In agreement with previous suggestions [6-8], we noted that metabolic control had a considerable influence on the time interval between onset of disease and onset of proteinuria. However, if one compares patients who never developed proteinuria and those who did, considerable overlap of the median blood glucose levels is apparent. Both in patients who subsequently became proteinuric and those who did not, no correlation was found between blood pressure and the quality of metabolic control. This indicates that it is presumably not low blood pressure which protects some poorly-controlled diabetic patients from developing proteinuria. Like Anderson et al. [18] we were able to show two frequency peaks for the onset of persistent proteinuria. In addition, the onset of clinical nephropathy seems to be earlier in males. This might indicate a genetically-determined heterogeneity of diabetic nephropathy.

Our data on patients with persistent proteinuria confirm the previous observations of Mogensen et al. [2] and Parving et al. [3] that blood pressure is a major determinant of the course of clinically overt nephropathy. Fourteen percent of normotensive, but $67 \%$ of hypertensive patients with proteinuria developed renal failure, i. e. elevated serum creatinine, during a median observation period after the onset of proteinuria of 3 years. The influence of hypertension was also striking after serum creatinine had risen above normal, since decay of renal function was related to blood pressure status. However, as in other studies [19-21], we were unable to detect a relationship between systolic or diastolic blood pressure values, on the one hand, and the time interval between onset of persistent proteinuria and increase of serum creatinine or the slope of decay of renal function, on the other. As discussed by others [21], this may be due to the fact that only a minority of our hypertensive patients had diastolic blood pressure $>100 \mathrm{mmHg}$. Such high diastolic pressures seem to be largely responsible for the correlation between blood pressure and the fall of glomerular filtration rate described by Mogensen [1]. Blood glucose levels at the time of persistent proteinuria did not predict the risk of developing renal failure because no striking difference of metabolic control could be detected between patients who went into renal failure and those who did not (Table 3). However, in the patients whose serum creatinine rose above normal, a significant correlation was noted between blood glucose levels (before and after onset of persistent proteinuria) and the time interval between onset of proteinuria and onset of renal failure. The results are compatible with the notion that metabolic control continues to influence the course of nephropathy even after persistent proteinuria had developed [11]. So far only Viberti et al. [12] have failed to find an effect of near-normalisation of metabolic control by insulin pump therapy on the further decay of renal function in a small group of dia- 
betic patients with proteinuria $(n=3)$. Only when serum creatinine has risen above normal can no further influence of metabolic control on the course of nephropathy be established. These findings are in agreement with the observation of other groups $[10,12]$ that further deterioration of renal function in such patients cannot thus be prevented, even by near-normalisation of metabolic control.

\section{References}

1. Mogensen CE (1976) Progression of nephropathy in long-term diabetics with proteinuria and effect of initial anti-hypertensive treatment. Scand J Clin Lab Invest 36: 384-388

2. Mogensen CE (1982) Long-term antihypertensive treatment inhibiting progression of diabetic nephropathy. $\mathrm{Br}$ Med $\mathbf{J} 285$ : 685-688

3. Parving HH, Andersen AR, Smidt UM, Svendsen PA (1983) Early aggressive anti-hypertensive treatment reduces rate of decline in kidney function in diabetic nephropathy. Lancet 1: 1175-1179

4. Hostetter THH, Troy JL, Brenner BM (1981) Glomerular hemodynamics in experimental diabetes mellitus. Kidney Int 19:410-415

5. Michels LD, Davidman M, Keane WF (1981) Determinants of glomerular filtration and plasma flow in experimental diabetic rats. J Lab Clin Med 98: 869-885

6. Pirart J (1977) Diabéte et complications dégénératives. Présentation d'une étude prospective portant sur 4400 cas observés entre 1947 et 1973 (deuxième partie). Diabete Metab 3: 173-182

7. Takazakura E, Nakamoto Y, Hayakawa H, Kawai K, Muramoto S, Yoshida K, Shimizu M, Shinoda A, Takeuchi J (1975) Onset and progression of diabetic glomerulosclerosis. Diabetes 24: 1-9

8. Deckert T, Poulsen JE (1981) Diabetic nephropathy: fault or destiny? Diabetologia 21: 178-183

9. Mogensen CE, Christensen CK, Vittinghus E (1983) The stages in diabetic renal disease with emphasis on the stage of incipient diabetic nephropathy. Diabetes 32: 64-78

10. Tamborlane WV, Puklin JE, Bergman M, Verdonk C, Rudolf MC, Felig P, Genel M, Sherwin R (1982) Long-term improvement of metabolic control with the insulin pump does not reverse diabetic microangiopathy. Diabetes Care 5 (Suppl 1): 58-64
11. Holman RR, Dornan TL, Mayon-White V, Howard-Williams J, Orde-Peckar C, Jenkins L, Steemson J, Rolfe R, Smith B, Barbour D, McPherson K, PYW Poon, Rizza C, Mann JI, Knight AH, Bron AJ, Turner RC (1983) Prevention of deterioration of renal and sensory nerve function by more intensive management of insulin-dependent diabetic patients. Lancet 1: 204-208

12. Viberti GC, Bilous RW, Mackintosch D, Bending JJ, Keen $\mathrm{H}$ (1983) Long-term correction of hyperglycaemia and progression of renal failure in insulin-dependent diabetes. Br Med J 286: $598-602$

13. Gyure WL (1977) Comparison of several methods of semi-quantitative determination of urinary protein. Clin Chem 23:876-879

14. Popper H, Mandel E, Mayer H (1937) Zur Kreatininbestimmung im Blute. Biochem Z 291: 354-358

15. Wiseman M, Viberti G, Mackintosh D, Jarrett RJ, Keen H (1984) Glycaemia, arterial pressure and micro-albuminuria in Type 1 (insulin-dependent) diabetes mellitus. Diabetologia 26: 401-405

16. Mathiesen ER, Oxenbøll B, Johansen K, Svendsen PAa, Deckert $T$ (1984) Incipient nephropathy in Type 1 (insulin-dependent) diabetes. Diabetologia 26: 406-410

17. Knowler WC, Bennett PH, Ballantine EJ (1980) Increased incidence of retinopathy in diabetics with elevated blood pressure. New Engl J Med 302: 645-650

18. Andersen AR, Sandahl Christiansen J, Andersen JK, Kreiner S, Deckert T (1983) Diabetic nephropathy in Type 1 (insulin-dependent) diabetes: an epidemiological study. Diabetologia 25: 496-501

19. Jones RH, Hayakawa H, Mackay JD, Parsons V, Watkins PJ (1979) Progression of diabetic nephropathy. Lancet 1: 1105-1106

20. Parving H-H, Smidt UM, Friisberg B, Bonnevie-Nielsen V, Andersen AR (1981) A prospective study of glomerular filtration rate and arterial blood pressure in insulin-dependent diabetics with diabetic nephropathy. Diabetologia 20: 457-461

21. Viberti GC, Bilous RW, Mackintosh D, Keen H (1983) Monitoring glomerular function in diabetic nephropathy. A prospective study. Am J Med 74: 256-264

Received: 4 May 1984

and in revised form: 11 October 1984

Dr. Ch. Hasslacher

Medizinische Universitätsklinik

Bergheimer Straße 58

D-6900 Heidelberg

FRG 